\title{
Hypovitaminosis D in Adults Living in a Sunny City: Relation to Some Cardiometabolic Risk Factors, National Food and Nutrition Surveillance
}

\author{
Bahareh Nikooyeh ${ }^{1}$, Majid Hajifaraji ${ }^{2}$, Amir-Hossein Yarparvar ${ }^{3}$, Zahra Abdollahi ${ }^{4}$, Mahnoosh Sahebdel ${ }^{5}$, Amaneh Mosayebi \\ Dehkordi $^{5}$, Dena Norouzi ${ }^{6}$, Seyed Masoumeh Taghizadeh ${ }^{5}$, Ali Kalayi ${ }^{1}$, Nastaran Shariatzadeh ${ }^{1}$, Maliheh Zahedirad ${ }^{1}$, Tirang \\ Neyestani $^{*}$ \\ 1- Laboratory of Nutrition Research, National Nutrition and Food Technology Research Institute and Faculty of Nutrition Sciences and Food \\ Technology, Shahid Beheshti University of Medical Sciences, Tehran, Iran. \\ 2- Department of Nutritional Policy-Making Research, National Nutrition and Food Technology Research Institute and Faculty of Nutrition Sciences and \\ Food Technology, Shahid Beheshti University of Medical Sciences, Tehran, Iran. \\ 3- UNICEF Office, Tehran 193951176, Iran. \\ 4- Nutrition Office, Iran Ministry of Health, Iran. \\ 5- Department of Health, Ahvaz University of Medical Sciences, Ahvaz, Iran. \\ 6- Ahvaz West Health Center, Ahvaz University of Medical Sciences, Ahvaz, Iran.
}

\section{A B S T R A C T}

Background and Objectives: Reports indicate that hypovitaminosis D is extremely common worldwide and is reemerging as a major health problem globally. In the present study, the main objectives were: 1) to examine whether healthy men and women living in Ahvaz have adequate vitamin D status; 2) to assess association between vitamin D status and some cardiometabolic risk factors.

Materials and Methods: This was a cross-sectional study which was part of the National Food and Nutrition Surveillance (NFNS). A total of 235 apparently healthy women and men aged 20-60 met the inclusion criteria from the city of Ahvaz (latitude $31.3^{\circ} \mathrm{N}, 48.6^{\circ} \mathrm{E}$ ). Anthropometric measurements including weight and height were taken. Serum $25-$ hydroxyvitamin D $(25(\mathrm{OH}) \mathrm{D})$ concentrations and lipid profile including triglycerides, total cholesterol, LDL-C and HDL$\mathrm{C}$ were evaluated.

Results: Mean circulating 25(OH)D concentration was $25.4 \pm 12.7 \mathrm{nmol} / \mathrm{L}$, with significant difference between men and women $(p=0.015)$. Only $6 \%$ of the participants had sufficient levels of vitamin $\mathrm{D}(25(\mathrm{OH}) \mathrm{D} \geq 50 \mathrm{nmol} / \mathrm{L})$. Results of logistic regression analyses after controlling for gender showed that subjects with hypovitaminosis D were almost 4.38 times more likely to be overweight/obese compared with subjects with vitamin D sufficiency (OR:4.38, p:0.011). There was no significant association between serum $25(\mathrm{OH})$ D concentration and the lipid profile components.

Conclusions: We found high prevalence of hypovitaminosis D in apparently healthy adults in Ahvaz, a sunny city of Iran. Our findings suggest that high vitamin D concentrations among the adult population are associated with a substantial decrease in body mass index. However, there was no association with the lipid profile components.

Keywords: Vitamin D, Ahvaz, Cardiometabolic risk factors

\section{Introduction}

Upon discovery of vitamin D and anti-rachitic properties of both cod liver oil and solar beam, it was naively thought that vitamin $\mathrm{D}$ deficiency could be simply eradicated from the world (1). Reports indicate that hypovitaminosis $\mathrm{D}$ is extremely common worldwide and is re-emerging as a major health problem globally (2).
Vitamin D is provided from food sources or is synthesized in the skin after sunlight exposure. Natural sources of vitamin D in foods are not sufficient to supply the normal body requirements, therefore, skin synthesis of vitamin D after ultraviolet radiation exposure is the main source of vitamin $\mathrm{D}$ (3). Regarding the significant role of sunlight in vitamin D synthesis, it is assumed to have a low 
prevalence of hypovitaminosis D in sunny regions. However, in spite of great annual sunshine time in sunny regions around the world, studies in Australia, India, Hawaii and Turkey reported a high prevalence of vitamin D deficiency (4-7). Several studies across the Iranian population have demonstrated high prevalence of vitamin D deficiency and insufficiency (8-10). Factors like behaviors of avoiding sunlight, clothing which prevents or minimizes sunlight exposure, high pollution levels could be the reasons for this condition.

It is well-known for a long time that vitamin D has a role in calcium metabolism and its undesirable status is associated with bone disorders (11). Moreover, recent studies have indicated that hypovitaminosis D may have non-musculoskeletal consequences including increased risks of chronic diseases such as type 1 and 2 diabetes mellitus, cardiovascular disease (CVD), hypertension, multiple sclerosis, variety of cancers and obesity (12). An inverse association between vitamin $\mathrm{D}$ status and cardiometabolic risk factors including adiposity, glucose tolerance, lipid profiles and blood pressure has been supported in a number of studies (13-14). Thus high prevalence of hypovitaminosis D may increase the incidence of these chronic diseases, especially cardiovascular disease in the future. However, the evidence of associations in different populations is scarce.

In the present study, the main objectives were: 1) to examine whether healthy men and women living in Ahvaz (a city located at the south west of Iran with high amounts of sunlight all year round) have adequate vitamin D status, and 2) to assess associations between vitamin D status and some cardiometabolic risk factors (CMRFs).

\section{Materials and Methods}

Study design: This was an analytical cross-sectional study which was part of the National Food and Nutrition Surveillance (NFNS). This is an ongoing population-based survey conducted periodically in Iran by National Nutrition and Food Technology Research Institute (NNFTRI) with assistance of United Nations Children's Fund (UNICEF) and Nutrition Office of the Deputy of Health of Iran, Ministry of Health (MOH) to assess the nutritional status of a large representative sample of the Iranian population over time. The ethical committee of NNFTRI approved the protocol of NFNS and informed written consents were obtained from all participants in the study.

The subjects were excluded if (i) they had evident diseases (diabetes mellitus, cancer, etc.) or (ii) they were on any form of drug treatment with possible effect on vitamin D metabolism. After screening, a total of 235 apparently healthy women and men aged 20-60 met the inclusion criteria from the city of Ahvaz (latitude $31.3^{\circ} \mathrm{N}, 48.6^{\circ} \mathrm{E}$, south-west part of Iran). In this study, high body mass index ( $>25$ $\left.\mathrm{kg} / \mathrm{m}^{2}\right)$, low high-density lipoprotein cholesterol $(<40$ $\mathrm{mg} / \mathrm{dl}$ in males and $<50 \mathrm{mg} / \mathrm{dl}$ in females) and high triglycerides $(>150 \mathrm{mg} / \mathrm{dl})$ were considered as cardiometabolic risk factors.

Anthropometrics: Anthropometric measurements including weight and height were taken using a standard digital weighing scale and stadiometer, respectively. All measurements were conducted by trained staff and quality checks were performed regularly. Body mass index (BMI) was calculated as the ratio of weight $(\mathrm{kg})$ over height squared $\left(\mathrm{m}^{2}\right)$. Overweight and obesity were defined using the BMI range of $25-30$ and more than $30 \mathrm{~kg} / \mathrm{m}^{2}$, respectively.

Laboratory investigations: Blood samples were collected after overnight fasting. After 30 minutes at room temperature (RT), sera were recovered, aliquoted in fresh micotubes then transferred to $-20^{\circ} \mathrm{C}$ freezer. Sera were immediately submitted to the Laboratory of Nutrition Research, NNFTRI, where the samples were kept in $-80^{\circ} \mathrm{C}$ until analysis. Serum 25-hydroxyvitamin D $\quad\left(\begin{array}{llll}25 & (\mathrm{OH}) & \mathrm{D}\end{array}\right)$ concentrations, the indicator of vitamin $\mathrm{D}$ status, were measured using a direct enzyme-linked immunoassay (EIA) (DIAsource, Louvain-la-Neuve, Belgium). Vitamin D status was categorized based on serum $25(\mathrm{OH}) \mathrm{D}$ concentrations as adequate $(>50 \mathrm{nmol} / \mathrm{L})$, insufficient $(25-50 \mathrm{nmol} / \mathrm{L})$, and deficient $(<25$ $\mathrm{nmol} / \mathrm{L})(15)$.

Serum lipid profile including triglycerides (TG), total cholesterol (TC), low-density lipoproteincholesterol (LDL-C) and high-density lipoproteincholesterol (HDL-C) were evaluated by enzymatic methods (Pars Azmoon, Tehran, Iran) and an autoanalyzer (Selectra E; Vitalab, Holliston, the Netherlands).

Statistical analyses: Quantitative variables were presented as means $\pm \mathrm{SD}$, while categorical variables were expressed as frequencies and percentages. Independent $t$ test and Chi square test were used in 
univariate analysis. Associations between continuous variables were examined by Pearson's correlation coefficient.

Multiple logistic regression was conducted by adjusting for gender to predict the risk of weight problems significantly associated with hypovitaminosis D. Data were analyzed using Statistical Package for Social Sciences (SPSS version 21.0 for Windows Smart Viewer). $P$ values of $<0.05$ were considered statistically significant.

\section{Results}

The main baseline characteristics of the studied participants are presented in Table 1. From 235 participants in this study, $50.2 \%$ were women. The mean age was $37.6 \pm 8.5$ years. Mean circulating $25(\mathrm{OH}) \mathrm{D}$ concentration was $25.4 \pm 12.7 \mathrm{nmol} / \mathrm{L}$, with significant difference between men and women $(\mathrm{p}=0.015)$.

About $67.8 \%$ of men and $70.1 \%$ of women were overweight/obese $\left(\mathrm{BMI}>25 \mathrm{~kg} / \mathrm{m}^{2}\right)$. Serum $25(\mathrm{OH}) \mathrm{D}$ concentrations were inversely correlated with BMI $(r=-0.184, \mathrm{p}=0.007)$. Overweight/obese subjects had significantly lower serum 25(OH)D concentrations than normal weight people ( $23.7 \pm 9.8$ vs. $29.2 \pm 17.5$ $\mathrm{nmol} / \mathrm{L}, \mathrm{p}=0.014)$.

Females were found to have significantly higher BMI $(\mathrm{p}=0.047)$ and serum HDL concentrations $(\mathrm{p}<0.001)$ than males (Table 1).

Distribution frequencies of $25(\mathrm{OH}) \mathrm{D}$ values are given in Table 2. Only $6 \%$ of the participants had sufficient levels of vitamin $\mathrm{D}(25(\mathrm{OH}) \mathrm{D} \geq 50$ $\mathrm{nmol} / \mathrm{L})$. Almost $29 \%$ of total subjects exhibited vitamin D insufficiency $(25(\mathrm{OH}) \mathrm{D}>25$ and $<50$ $\mathrm{nmol} / \mathrm{L})$.

Results of logistic regression analysis after controlling for gender showed that subjects with hypovitaminosis D were almost 4.38 times more likely to be overweight/obese compared with subjects with vitamin D sufficiency (OR:4.38, CI, 1.4-13.4, $\mathrm{p}: 0.011)$. It was found that the increased risk of overweight was started at $25(\mathrm{OH}) \mathrm{D}$ less than 46 nmol/L significantly (OR: 3.08, CI, 1.09-8.56, p:0.032).

There was no significant association between serum $25(\mathrm{OH}) \mathrm{D}$ concentration and the lipid profile components[TG (r:-0.065, p:0.321),Tchol (r: -0.078, p:0.234), LDL (r:-0.059,p:0.372),HDL (r: -0.057, p: 0.386)].

Table 1. Baseline characteristics of participants by gender

\begin{tabular}{|c|c|c|c|c|}
\hline Variables & $\begin{array}{c}\text { Total } \\
(n=235)\end{array}$ & $\begin{array}{c}\text { Men } \\
(n=117)\end{array}$ & $\begin{array}{l}\text { Women } \\
(\mathrm{n}=118)\end{array}$ & $p$-value \\
\hline Age (years) & $37.6 \pm 8.5$ & $37.7 \pm 8.1$ & $37.4 \pm 9.0$ & 0.801 \\
\hline Serum $25(\mathrm{OH}) \mathrm{D}(\mathrm{nmol} / \mathrm{L})$ & $25.4 \pm 12.7$ & $27.5 \pm 13.5$ & $23.3 \pm 12.0$ & 0.015 \\
\hline Weight (Kg) & $76.9 \pm 15.8$ & $81.5 \pm 16.0$ & $72.3 \pm 14.1$ & $<0.001$ \\
\hline Height $(\mathrm{cm})$ & $166.8 \pm 9.4$ & $173.9 \pm 6.6$ & $159.8 \pm 6.0$ & $<0.001$ \\
\hline $\operatorname{BMI}\left(\mathrm{Kg} / \mathrm{m}^{2}\right)$ & $27.6 \pm 5.3$ & $26.9 \pm 5.0$ & $28.3 \pm 5.4$ & 0.047 \\
\hline Serum Triglyceride (mg/dL) & $118.9 \pm 88.6$ & $138.0 \pm 91.5$ & $99.7 \pm 81.5$ & 0.001 \\
\hline Total cholesterol (mg/dL) & $172.9 \pm 40.5$ & $173.8 \pm 44.3$ & $172.0 \pm 36.3$ & 0.742 \\
\hline $\mathrm{LDL}(\mathrm{mg} / \mathrm{dL})$ & $100.2 \pm 28.2$ & $101.3 \pm 27.0$ & $99.1 \pm 29.4$ & 0.556 \\
\hline HDL (mg/dL) & $46.8 \pm 12.5$ & $42.1 \pm 11.1$ & $51.5 \pm 12.2$ & $<0.001$ \\
\hline \multicolumn{5}{|l|}{ Sun exposure n $(\%)$} \\
\hline$<1 \mathrm{hr}$ & $180(76.6)$ & $77(65.3)$ & $103(88.0)$ & $<0.001$ \\
\hline$>1 \mathrm{hr}$ & $55(23.4)$ & $41(34.7)$ & $14(12.0)$ & \\
\hline
\end{tabular}

Table2. Prevalence of vitamin D deficiency, insufficiency, and sufficiency

\begin{tabular}{lllll}
\hline & Total, $\mathrm{n}(\%)$ & Men, n $(\%)$ & Women, $\mathrm{n}(\%)$ & $p$-value \\
& $95 \% \mathrm{CI}$ & $95 \% \mathrm{CI}$ & $95 \% \mathrm{CI}$ & \\
\hline deficiency & $154(65.5)$ & $68(57.6)$ & $86(73.5)$ & 0.037 \\
& $60.5-70.5$ & $50.6-64.6$ & $68.5-78.5$ & \\
Insufficiency & $67(28.5)$ & $41(34.7)$ & $26(22.2)$ & \\
& $25.5-31.5$ & $29.7-39.7$ & $17.2-27.2$ & \\
sufficiency & $14(6.0)$ & $9(7.6)$ & $5(4.3)$ & \\
& $3.0-9.0$ & $4.6-11.6$ & $3.3-5.3$ & \\
\hline
\end{tabular}




\section{Disc ussion}

Our study demonstrated a high occurrence of undesirable vitamin D status (approximately 94\%) among the participants. Hypovitaminosis D was common even in people with self-reported sun exposure exceeding one hour per day.

There are several studies reporting low serum vitamin $25(\mathrm{OH}) \mathrm{D}$ in populations across the world in both sexes and all age groups of the population, including over $84 \%$ of apparently healthy adults of both sexes in China (16), 90\% of the population in Qatar (17), 70-97\% of population in Canada (18) and $51 \%$ of adults in Hawaii, a very sunny region (19). In this regard, two points must be taken into consideration. Firstly, in all these, and many other studies, the cutoff used for serum 25(OH)D to define vitamin $\mathrm{D}$ inadequacy is $75 \mathrm{nmol} / \mathrm{L}(16-17,19)$ or even higher (18). In the current study, we categorized calcidiol concentrations less than $50 \mathrm{nmol} / \mathrm{L}$ as poor vitamin D status, according to the Institute of Medicine (IOM) (20). With higher cutoff points, almost 100 percent of the studied population could be considered as having poor vitamin D status. Secondly, some studies confirm our findings that living in a sunny region does not necessarily protect the residences against vitamin D deficiency (19). Sun exposure behaviors and socio-cultural factors are important determinants.

In the present study, women had significantly lower mean vitamin D levels than men. There are reports that vitamin D deficiency or insufficiency is more severe in women (21-22). This difference may be due to higher fat mass in the female body. The other explanation could be type of clothing in the Islamic countries which leaves little of the skin exposed to sunlight. Although Ahvaz usually has a sunny climate almost all year round, local people usually avoid direct sun exposure due to many reasons including cultural issues, excessive heat and potential health risks of solar exposure. Air pollution and limited outdoor activity probably also plays an important role in big populated cities (23).

Our findings showed a significant association of hypovitaminosis D with BMI, which supports previous reports (24-25). Noteworthy, risk of overweight/obesity rose significantly as serum 25(OH)D declined below $46 \mathrm{nmol} / \mathrm{L}$.

An inverse association between vitamin D status and adiposity has been supported in a number of earlier studies (14, 26-28). However, the mechanism underlying these associations is not fully known. There are some proposed mechanisms for the impact of vitamin $\mathrm{D}$ on adiposity. It was proposed that the association between serum $25(\mathrm{OH}) \mathrm{D}$ and adiposity could be explained by an increased sequestration of $25(\mathrm{OH}) \mathrm{D}$ in the larger body pool of fat of obese subjects (25).

A study showed that the increase in blood $25(\mathrm{OH}) \mathrm{D}$ concentrations was $57 \%$ less in the obese than in the non-obese subjects $24 \mathrm{~h}$ after exposure to an identical amount of UV-B irradiation. However, the content of the vitamin D3 precursor 7dehydrocholesterol in the skin and the percentage conversion to pre-vitamin D3 and vitamin D3 were not significantly different between obese and nonobese subjects (25).

On the other hand, vitamin D deficiency results in hyperparathyroidism which elevates calcium influx into the adipocytes wherein lipogenesis is enhanced by calcium. As a result, weight gain may be promoted due to the increased PTH secretion (29-30).

This association between vitamin $\mathrm{D}$ status and body adiposity suggests that undesirable vitamin D status may play a role at the early stages of number of high BMI-related chronic diseases. Although this does not prove a causative effect, it is highly suggestive and warrants further clinical trials.

We found no significant association between vitamin D status and lipid profile components. Several studies have reported the relationship between circulating $25(\mathrm{OH}) \mathrm{D}$ concentrations and lipid profile in different age and sex subgroups (31-34). However, in some other studies no association has been observed (35). The relation between vitamin D status and lipid profile is, therefore, still controversial and needs further well-designed randomized controlled clinical trials (36).

In the current study, all serum samples were analyzed in the Laboratory of Nutrition Research to eliminate inter-laboratory variations. However, our study has some limitations. Because it was a crosssectional study, we cannot be certain that vitamin D status affected BMI rather than vice versa.

\section{Conclusion}

We found the high prevalence of hypovitaminosis $\mathrm{D}$ in apparently healthy adults in Ahvaz indicating that living in a sunny city cannot necessarily be protective against vitamin D deficiency. Our findings 
suggest that the high status of vitamin D among the adult population is associated with a substantial decrease in body mass index.

\section{Ac knowledgement}

This study is based on data collected in the context of the National Food and Nutrition Surveillance (NSNS), which is largely funded by the United Nations Children's Fund (UNICEF) and Nutrition Office of the Deputy of Health of Iran Ministry of Health $(\mathrm{MOH})$.

The authors wish to thank the participants for taking part in this project.

\section{Financial disclosure}

The author declares no conflict of interest

\section{References}

1. Rajakumar K. Vitamin D, cod-liver oil, sunlight, and rickets: a historical perspective. Pediatrics. 2003 Aug;112(2):e132-5.

2. Mithal A, Wahl DA, Bonjour J-P, Burckhardt $P$, Dawson-Hughes B, Eisman JA, et al. Global vitamin D status and determinants of hypovitaminosis D. Osteoporosis International. 2009;20(11):1807-20.

3. Grant WB, Holick MF. Benefits and requirements of vitamin D for optimal health: a review. Altern Med Rev. 2005;10(2):94-111.

4. Binkley N, Novotny R, Krueger D, Kawahara T, Daida Y, Lensmeyer G, et al. Low vitamin D status despite abundant sun exposure. The Journal of Clinical Endocrinology \& Metabolism. 2007;92(6):2130-5.

5. Guzel R, Kozanoglu E, Guler-Uysal F, Soyupak S, Sarpel T. Vitamin D status and bone mineral density of veiled and unveiled Turkish women. Journal of women's health \& gender-based medicine. 2001;10(8):765-70.

6. Goswami R, Kochupillai N, Gupta N, Goswami D, Singh N, Dudha A. Presence of $25(\mathrm{OH}) \mathrm{D}$ deficiency in a rural North Indian village despite abundant sunshine. JAPI. 2008;56:755-7.

7. Daly RM, Gagnon C, Lu ZX, Magliano DJ, Dunstan DW, Sikaris KA, et al. Prevalence of vitamin D deficiency and its determinants in Australian adults aged 25 years and older: a national, population-based study. Clinical endocrinology. 2012;77(1):26-35.

8. Maghbooli Z, Hossein-Nezhad A, Shafaei AR, Karimi F, Madani FS, Larijani B. Vitamin D status in mothers and their newborns in Iran. BMC Pregnancy Childbirth. 2007;7:1.

9. Moussavi M, Heidarpour R, Aminorroaya A, Pournaghshband Z, Amini M. Prevalence of vitamin D deficiency in Isfahani high school students in 2004. Horm Res. 2005;64(3):144-8.
10. Neyestani TR, Hajifaraji M, Omidvar N, Eshraghian MR, Shariatzadeh N, Kalayi A, et al. High prevalence of vitamin D deficiency in school-age children in Tehran, 2008: a red alert. Public Health Nutr. 2012 Feb;15(2):324-30.

11. DeLuca HF. Overview of general physiologic features and functions of vitamin D. The American journal of clinical nutrition. 2004;80(6):1689S-96S.

12. Holick MF, Chen TC. Vitamin D deficiency: a worldwide problem with health consequences. The American journal of clinical nutrition. 2008;87(4):1080S-6S.

13. Scragg R, Sowers M, Bell C. Serum 25-hydroxyvitamin $\mathrm{D}$, diabetes, and ethnicity in the Third National Health and Nutrition Examination Survey. Diabetes care. 2004;27(12):2813-8.

14. Hyppönen E, Boucher BJ, Berry DJ, Power C. 25hydroxyvitamin D, IGF-1, and metabolic syndrome at 45 years of age. Diabetes. 2008;57(2):298-305.

15. Thacher TD, Clarke BL, editors. Vitamin D insufficiency. Mayo Clinic Proceedings; 2011: Elsevier.

16. Lu H-K, Zhang Z, Ke Y-H, He J-W, Fu W-Z, Zhang C$\mathrm{Q}$, et al. High prevalence of vitamin D insufficiency in China: relationship with the levels of parathyroid hormone and markers of bone turnover. PloS one. 2012;7(11):e47264.

17. Badawi A, Arora P, Sadoun E, Al-Thani A-A, Al Thani MH. Prevalence of vitamin D insufficiency in Qatar: a systematic review. Journal of public health research. 2012;1(3):229.

18. Schwalfenberg G, Genuis S, Hiltz M. Addressing vitamin D deficiency in Canada: a public health innovation whose time has come. Public health. 2010;124(6):350-9.

19. Binkley N, Novotny R, Krueger D, Kawahara T, Daida YG, Lensmeyer G, et al. Low vitamin D status despite abundant sun exposure. The Journal of Clinical Endocrinology \& Metabolism. 2007;92(6):2130-5.

20. Institute of Medicine (IOM). Dietary Reference Intakes for Calcium and Vitamin D. Washington, DC: National Academies Press; 2011.

21. van Dam RM, Snijder MB, Dekker JM, Stehouwer CD, Bouter LM, Heine RJ, et al. Potentially modifiable determinants of vitamin D status in an older population in the Netherlands: the Hoorn Study. The American journal of clinical nutrition. 2007;85(3):755-61.

22. Looker AC, Dawson-Hughes B, Calvo M, Gunter E, Sahyoun N. Serum 25-hydroxyvitamin D status of adolescents and adults in two seasonal subpopulations from NHANES III. Bone. 2002;30(5):771-7.

23. Agarwal K, Mughal M, Upadhyay P, Berry J, Mawer E, Puliyel J. The impact of atmospheric pollution on vitamin D status of infants and toddlers in Delhi, India. Archives of disease in childhood. 2002;87(2):111-3. 
24. Snijder MB, van Dam RM, Visser M, Deeg DJ, Dekker JM, Bouter LM, et al. Adiposity in relation to vitamin D status and parathyroid hormone levels: a populationbased study in older men and women. The Journal of Clinical Endocrinology \& Metabolism. 2005;90(7):4119-23.

25. Wortsman J, Matsuoka LY, Chen TC, Lu Z, Holick MF. Decreased bioavailability of vitamin D in obesity. The American journal of clinical nutrition. 2000;72(3):690-3.

26. Reis JP, von Mühlen D, Miller ER, Michos ED, Appel LJ. Vitamin D status and cardiometabolic risk factors in the United States adolescent population. Pediatrics. 2009;124(3):e371-e9.

27. Barja-Fernández S, Aguilera CM, Martínez-Silva I, Vazquez R, Gil-Campos M, Olza J, et al. 25Hydroxyvitamin D levels of children are inversely related to adiposity assessed by body mass index. Journal of Physiology and Biochemistry. 2017:1-8.

28. Cordeiro A, Santos A, Bernardes M, Ramalho A, Martins MJ. Vitamin D metabolism in human adipose tissue: could it explain low vitamin D status in obesity? Hormone Molecular Biology and Clinical Investigation. 2017.

29. Zemel MB. Regulation of adiposity and obesity risk by dietary calcium: mechanisms and implications. Journal of the American College of Nutrition. 2002;21(2):146S$51 \mathrm{~S}$.

30. McCarty M, Thomas C. PTH excess may promote weight gain by impeding catecholamine-induced lipolysis-implications for the impact of calcium, vitamin $\mathrm{D}$, and alcohol on body weight. Medical hypotheses. 2003;61(5):535-42.

31. Jorde R, Figenschau Y, Hutchinson M, Emaus N, Grimnes G. High serum 25-hydroxyvitamin D concentrations are associated with a favorable serum lipid profile. Eur J Clin Nutr. 2010 Dec;64(12):145764.

32. Birken CS, Lebovic G, Anderson LN, McCrindle BW, Mamdani M, Kandasamy S, et al. Association between Vitamin D and Circulating Lipids in Early Childhood. PLoS One. 2015;10(7):e0131938.

33. Sun $X$, Cao ZB, Tanisawa K, Ito T, Oshima S, Ishimi $\mathrm{Y}$, et al. Associations between the Serum 25(OH)D Concentration and Lipid Profiles in Japanese Men. J Atheroscler Thromb. 2015;22(4):355-62.

34. Lepsch J, Eshriqui I, Farias DR, Vaz JS, Cunha Figueiredo AC, Adegboye AR, et al. Association between early pregnancy vitamin $\mathrm{D}$ status and changes in serum lipid profiles throughout pregnancy. Metabolism. 2017 May;70:85-97.

35. Ponda MP, Huang X, Odeh MA, Breslow JL, Kaufman HW. Vitamin D may not improve lipid levels: a serial clinical laboratory data study. Circulation. $2012 \mathrm{Jul}$ 17;126(3):270-7.

36. Nkooyeh B, Neyestani T. Cholesterol and vitamin D: how the 'mother'and 'daughter'molecules interact. Handbook of cholesterol: Wageningen Academic Publishers; 2016. p. 256-65. 